\section{Maurizio Roncolato \\ Fabio Arpinelli \\ Laura Fabbri \\ Francesco Manetta \\ Giovanni Visonà \\ Ovidio Brignoli \\ Gerardo Medea}

\title{
The cost of the migraine patient in Italy
}

Received: 11 September 2000

Accepted in revised form: 5 January 2001

M. Roncolato • F. Arpinelli ( $\square)$

L. Fabbri • F. Manetta • G. Visonà

Medical Department,

Glaxo Wellcome,

Via A. Fleming 2, I-37135 Verona, Italy

e-mail: fa7463@glaxowellcome.co.uk

Tel.: +39-045-9218740

Fax: +39-045-9218193

O. Brignoli • G. Medea

Società Italiana di Medicina Generale,

Brescia, Italy

\begin{abstract}
To estimate the cost of the migraine patient in Italy, we undertook an observational, multicenter study. The study was carried out by 902 Italian general practitioners (GPs). GPs asked patients over 14 years of age who came to their surgeries whether they suffered from headaches. If so, the doctor questioned the patient to determine whether he or she was a migraineur according to the IHS criteria. Migraineurs entered a 2-month follow-up programme. GPs interviewed 72038 patients, of which 4794 were migraineurs. Migraineurs received a diary card to record attacks and the treatment they took. During the two scheduled monthly meetings with the doctor, patients and GPs recorded on diary cards the use of
\end{abstract}

healthcare resources and working days lost due to migraine. Overall, the annual cost of migraine per patient was Lit 1159840 (605.03 USD). Our study shows that the overall cost of migraine to the community is very high. Direct costs are higher than in other countries.

Key words Migraine $\cdot$ Cost of illness

\section{Introduction}

Despite the fact that migraine is frequent [1], many migraine sufferers do not consult a general practitioner (GP) for treatment. Migraineurs often treat themselves, usually with analgesics which can be bought without a prescription. In addition, most migraine sufferers know the factors which lead to their migraine and avoid the causes.

Lack of healthcare consultation and the low level of knowledge in non-specialists of the diagnostic criteria laid down by the International Headache Society (IHS) [2] make it difficult to estimate the prevalence of migraine, the number of migraine sufferers in a given population, the cost per patient and the overall cost for the population.
Recently, an Italian study has estimated the prevalence of migraine in Italy to be $11.4 \%$ of the adult population; this figure indicates a total number of 5.5 million migraine sufferers in Italy [3].

Although migraine is not a life-threatening disease, it does cause direct healthcare costs (examinations with and without instruments, treatment with anti-migraine drugs and hospitalisation) and other costs borne by consumers (many anti-migraine drugs and analgesics are partially or totally charged to consumers), and also reduces working days with a considerable loss in productivity on the national scale (indirect costs). It may also lead to discomfort and to a lower quality of life in health-related parameters, as has been reported in numerous publications [4-6].

There is little data in Italy on migraine-related costs. The 
cited Italian migraine study also collected data useful for estimating direct, indirect and total yearly costs. These data have been used in our study.

\section{Materials and methods}

The study was carried out in co-operation with Società Italiana di Medicina Generale (SIMG). In Italy, access to primary care is free for all, and this makes it easy to find appropriate healthcare.

Doctors taking part in the study were from all over Italy and volunteered their work in the study. During the study period, lasting 5 days over two consecutive weeks (the first 3 days of the first week and the second 2 days of the second week), doctors asked all patients over 14 years of age who came to their surgeries whether they suffered from headaches. If the answer was 'no', the contact was recorded and no action was taken. If the answer was 'yes', the doctor questioned the patient to determine whether he or she was a migraine sufferer according to the criteria of the IHS:

1. Pain with at least 2 of the following features: throbbing quality, lateralized, moderate-severe intensity, worsened by exertion;

2. At least one of the following symptoms: nausea, vomiting, photo- and phonophobia;

3. Duration of attacks ranging from 4 to 72 hours;

4. Occurrence of at least 5 attacks with the preceding features;

Patients who were positive for three of the listed features were considered to be "likely migraine sufferers".

Doctors also recorded characteristics of the migraine (e.g. intensity, frequency) which have been published, along with the epidemiological data, separately [3].

Patients considered to be migraine sufferers or likely migraine sufferers were placed on a 2-month follow-up programme. They were given a diary card to record attacks of migraine and the treatment they took in the weeks subsequent to attacks. During the two scheduled meetings with the doctor, after 1 and 2 months, patients and the GP filled in diary cards regarding the use of healthcare resources, examinations, diagnostics, hospitalisation and working days lost due to migraine over the previous 30 days.
The analysis of costs generated by migraine was conducted from a community perspective, taking into consideration both direct and indirect costs. Money values placed on the different cost items were obtained from official sources (drugs, medical examinations, diagnostic tests, hospitalisations) or from the literature (working days lost) [7] and are shown in Table 1.

The total cost of migraine in the Italian population was calculated using the following formula:

$$
\text { Total cost }=\text { Population } \times \text { Prevalence } \times \text { Cost per year }
$$

where total cost is that generated annually by migraine in Italy in the entire population over 14 years of age, population is the number of inhabitants over 14 years of age as of 31 December 1996 [8], prevalence is that of migraine estimated in a previous study [3], cost per year is the average annual cost per patient (i.e. 12-times the cost per month), and cost per month per patient is the average total cost of all resources recorded divided by the number of questionnaires returned.

\section{Results}

During the last quarter of 1996, 902 doctors interviewed 72 038 patients, of whom 71588 were evaluated (99\%); $38.9 \%$ were male and the average age was 51 years. Overall, 4794 migraine sufferers filled in 8541 questionnaires regarding the consumption of healthcare resources; the response rate was $89.1 \%$.

Direct costs for migraine for our sample were $52.4 \%$ of the whole, while the remainding $47.6 \%$ reflected indirect costs. Overall, the annual cost of migraine per patient was Lit 1 159840 (605.03 USD) (Table 2). A more detailed analysis shows that the cost of examinations (GPs' examinations, specialist examinations and first aid not leading to hospitalisation) was Lit 96660 (50.42 USD) per year. Diagnostic examinations (routine laboratory tests, electroencephalography, X-ray of the cranium and cervical portion of the spinal

Table 1 Direct and indirect costs of migraine in Italy

\begin{tabular}{|c|c|c|c|}
\hline & \multicolumn{2}{|c|}{ Unit cost } & \multirow[t]{2}{*}{ Reference } \\
\hline & ITL & USD & \\
\hline \multicolumn{4}{|l|}{ Direct costs } \\
\hline GP consultations, & & & [18] \\
\hline Office/surgery visits, & 25000 & 13.04 & \\
\hline Home visits & 50000 & 26.08 & \\
\hline Specialist consultations & 40000 & 20.86 & [19] \\
\hline Access to emergency/first aid (no hospitalization) & 40000 & 20.86 & [19] \\
\hline Hospitalisation (DRG 025) & 3654000 & 1906.10 & [20] \\
\hline \multicolumn{4}{|l|}{ Indirect costs } \\
\hline Working days & 200000 & 104.32 & [7] \\
\hline
\end{tabular}


Table 2 Cost per year of the migraine patient in Italy

\begin{tabular}{|c|c|c|c|}
\hline & Lit & USD & Percent of total cost \\
\hline \multicolumn{4}{|l|}{ Direct costs } \\
\hline Consultations & 96660 & 50.42 & 8.4 \\
\hline Diagnostics & 122790 & 64.05 & 10.6 \\
\hline Drugs & 83900 & 43.77 & 7.2 \\
\hline Hospitalisations & 304050 & 158.61 & 26.2 \\
\hline Total & 607400 & 316.85 & 52.4 \\
\hline \multicolumn{4}{|c|}{ Indirect costs due to working days lost } \\
\hline Total & 552440 & 288.18 & 47.6 \\
\hline Total cost & 1159840 & 605.03 & 100.0 \\
\hline
\end{tabular}

column, computed tomography, magnetic resonance imaging) cost Lit 122790 (64.05 USD) per year, drugs (40\% analgesics, 33\% non-steroid anti-inflammatory drugs, $24 \%$ anti-migraine drugs) cost Lit 83900 (43.77 USD) per year, and hospitalisation (one or more days) cost Lit 304050 (158.61 USD) per year.

On average, patients lost 2.76 working days, corresponding to an economic value of Lit 552.440 (288.18 USD).

On the national scale the number of working days lost was 15016870 days per year, corresponding to a value of over Lit 3000 bn (over 1560 million USD). This was calculated on the basis of productive members of the population (full and part-time workers), only $41.7 \%$ of migraine sufferers as a whole.

On the basis of epidemiological and economic data, the total number of migraine sufferers in Italy is over 5440000 people over age 14 years, with a total estimated cost of over Lit 6400 bn (over 3370 million USD) per year (Table 3).

Table 3 Cost of migraine in Italy

\begin{tabular}{lr}
\hline Italian population over 14 years of age & 49017544 \\
Prevalence of migraine & $11.39 \%$ \\
Number of migraineurs & 5583098 \\
Cost per year per patient & \\
$\quad$ Lit & 1159840 \\
USD & 605.03 \\
Cost per year in Italy & \\
$\quad$ Billion Lit & 6475 \\
$\quad$ Million USD & 3378 \\
\hline
\end{tabular}

\section{Discussion}

Our study had unavoidable methodological limitations. For example, the cost of the abuse of analgesics was not included, nor the impact of migraine on the quality of life in the patient. In addition, doctors recruited to the study were particularly sensitive to the problem of migraine during the study period, due to the object of the study itself, and this may have led to overestimates in the number of migraine sufferers. Furthermore, patients who habitually suffer from migraine may not have gone to their GP due to disappointing previous treatments or because the study period did not correspond with a migraine attack, they may have seeked treatment by other methods (e.g. alternative medicine), or they may have been self-treated.

Our study confirms that a large number of people suffer from migraine and the overall cost to the community is very high. In Italy, the majority of drug spending (analgesics and anti-migraine drugs) is partly or wholly borne by the patient, and the costs of hospitalisation and working days lost is very heavy. Overall, from our sample, direct costs were slightly higher than $50 \%$ of the total costs, whereas indirect costs were slightly lower.

In Europe, direct costs are relatively low, while they are higher in America [9]. This may be due to the habit in North America of patients going to specialists even at the early stage of a disease (for example, in Canada specialists are consulted by $41 \%$ of migraine sufferers, whereas the equivalent figure in Europe is 6\%-16\%), rather than going to a GP. The same study reported generally low costs for hospitalisation, both in Europe and the USA. In our sample, on the contrary, hospital costs were $26 \%$ of the total. This 
abnormal data may be due to the need to carry out specialist diagnostic examinations or differential diagnoses for other pathologies. A sharp reduction of hospital costs in Italy would reduce direct costs and bring data into line with other European countries.

The relevance of indirect costs, which in our sample were almost $50 \%$ of the total costs, but would be more than $50 \%$ if hospital costs were reduced, shows that migraine is a disease which has a strong impact on working days lost. It is well-known that migraine sufferers do miss work or work at reduced efficiency. Loss of productivity is not easy to calculate since the absence of an employee may be offset by colleagues or flexible working practices such as "flexitime" [10], with partial or complete recovery of the lost productivity. Nonetheless, since migraine is a chronic disease, the disability it causes is the highest cost for society as a whole $[11,12]$, making a calculation of long-term effects a worthwhile study [13].

The number of working days lost by our sample is in line with the results obtained in other European countries [9]. For the sake of simplicity, we did not calculate the loss of productivity of migraine sufferers remaining at work during attacks. If this had been calculated, the indirect costs of migraine would be even higher.

Our study did not have the aim of analysing the costs of different types of drugs used as treatment. Nevertheless, it can be estimated that the widespread use of specific antimigraine drugs for treatment causes a general reduction in the overall cost of migraine, due to fewer working days lost and reduced productivity losses, despite the cost of the drugs themselves [16]. Treatment with sumatriptan reduces the number of doctor's examinations and other healthcare costs, and makes hospitalisation unlikely [14]. Moreover, patients treated for migraine with sumatriptan lost fewer working hours and worked more efficiently due to the effective and rapid onset of action of the drug [15].
Our study estimated costs of drugs entirely paid for by patients, as well as the cost of diagnostic examinations which patients pay for in part. Hence the direct cost we estimated is not totally borne by the national healthcare service.

The costs of migraine could be considerably reduced by a greater understanding of the criteria of the IHS by GPs, with better diagnostic facilities to reduce hospitalisations and by the properly targeted use of appropriate antimigraine drugs for therapy. The efficacy and rapid onset of action of anti-migraine drugs could reduce absenteeism and improve working efficiency. These measures would reduce overall migraine-related costs and help the healthcare service achieve a more rational use of resources, in line with modern requirements.

Aknowledgement This research was entirely supported by Glaxo Wellcome, Verona, Italy. We thank the Italian Society of General Practitioners (SIMG) and its President Prof. A. Pagni, as well as the general practitioners and local coordinators who took part, namely: Aramini E, Betetto V, Bevilacqua S, Bitetti R, Buffa G, Cancian G, Capone R, Caroselli A, Chieregato G, Cioffi M, Cocchi PC, Colella A, Colli M, Barucco F, Collegiani A, Cucchiara P, De Benedictis A, Di Maria F, D'Innocente G, Evangelista P, Filippi S, Franceschini G, Galassi R, Galasso M, Galvano L, Gambini A, Gandini T, Gerbaudo MG, Ghionda F, Griffa PG, Guerra A, Inferrera S, La Pace L, Malatesta M, Marciani ML, Marino S, Martini F, Massarini M, Mazzoleni F, Milani L, Morelli U, Morgana I, Mostacciolo F, Mureddu G, Muscetta S, Nuti C, Pais A, Pani I, Paradisi P, Parlanti R, Pavan M, Pedicino C, Piccinocchi G, Pietropaolo F, Pinna A, Pocorobba T, Proietto GR, Quattrocchi M, Raccone A, Raciti T, Ragone L, Ragone P, Salvetti A, Sandullo A, Sanfilippo O, Saponaro G, Scarabeo V, Scarano L, Scarrone G, Scialino G, Seminara N, Simone C, Spinnato L, Spitaleri G, Tarallo N, Tassinari E, Titta G, Toni A, Vento G, Ventriglia G, Zancanaro R, Zaninetti $\mathrm{P}$

\section{References}

1. Silberstein SD, Lipton RB (1993) Epidemiology of migraine. Neuroepidemiology 12:179-194

2. Headache Classification Committee of the International Headache Society (1988) Classification and diagnostic criteria for headache disorders, cranial neuralgias and facial pain. Cephalalgia 8[Suppl 7]:1-96
3. Roncolato M, Fabbri L, Recchia G et al (2000) An epidemiological study to assess migraine prevalence in a sample of Italian population presenting to their GPs. Eur Neurol 43:102-106

4. Monzon MJ, Lainez MJ (1998) Quality of life in migraine and chronic daily headache patients. Cephalalgia 18(9):638-643
5. Mannix LK, Solomon GD (1998) Quality of life in migraine. Clin Neurosci 5(1):38-42

6. Jhingran P, Cady RK, Rubino J et al (1996) Improvement in health related quality of life with sumatriptan treatment for migraine. J Fam Practice 42(1):36-42

7. De Carli G, Dal Negro R, Recchia G et al (1991) Bronchial asthma: pharmacoeconomic considerations. Rass Pat App Resp 6:45-46 
8. - (1997) Annuario Statistico Italiano, 34, Roma

9. Ferrari M (1998) The economic burden of migraine to society. Pharmacoeconomics 13(6):667-676

10. Cortelli P, Dahlof C, Bouchard J et al (1997) A multinational investigation of the impact of subcutaneous sumatriptan. III Workplace productivity and non-workplace activity.

Pharmacoeconomics 11:35-42

11. Schoenen J, Caekebeke J, Louis P et al (1993) A questionnaire-based survey of migraine in the Belgian population: prevalence, demography, socio-economic factors. In: 4th International Headache Research Seminar: Headache Classification and Epidemiology. Copenhagen, p 44
12. Clarke CE (1996) Economic and social impact of migraine. Qim Mon J Assoc Phys 89:77-84

13. Steiner TJ (1995) Long term cost-benefit assessment of anti-migraine drugs. Cephalalgia 15:37-40

14. Litaker DG, Solomon GD, Genzen JR (1996) Impact of sumatriptan on clinic utilization and costs of care in migraineurs. Headache 36:538-541

15. Laloux P, Vakaet A, Monseu G et al (1998) Subcutaneous sumatriptan compared with usual acute treatment for migraine: clinical and pharmaeconomic evaluation. Acta Neurol Belg 98:332-341
16. Blau JN, Drummond MF (eds) (1991) Migraine. Office of Health Economics, London

17. - (1996) Informatore farmaceutico. OEMF, Milano

18. - (1992) Official drug list. Ministerial Decree (DM) of 7 November 1991. Official Gazette (no. 128, 2 June 1992)

19. - (1996) Official drug list. Ministerial Decree (DM) of 22 July 1996. Official Gazette (no. 216, 14 September 1996)

20. - (1994) Le tariffe delle prestazioni di assistenza ospedaliera. Ministerial Decree (DM) of 14 December 1994. Official Gazette (no. 300, 24 December 1994) 